\title{
A phase 2 study of everolimus combined with trastuzumab and paclitaxel in patients with HER2-overexpressing advanced breast cancer that progressed during prior trastuzumab and taxane therapy
}

\author{
Sara A. Hurvitz • Florence Dalenc • Mario Campone - Ruth M. O'Regan • \\ Vivianne C. Tjan-Heijnen · Joseph Gligorov $\cdot$ Antonio Llombart • \\ Haresh Jhangiani - Hamid R. Mirshahidi • Elizabeth Tan-Chiu • Sara Miao • \\ Mona El-Hashimy $\cdot$ Jeremie Lincy $\cdot$ Tetiana Taran • Jean-Charles Soria • \\ Tarek Sahmoud · Fabrice André
}

Received: 28 June 2013/Accepted: 28 August 2013/Published online: 8 October 2013

(C) The Author(s) 2013. This article is published with open access at Springerlink.com

\begin{abstract}
Increased activation of the PI3K/Akt/mTOR pathway is a common factor in putative mechanisms of trastuzumab resistance, resulting in dysregulation of cell migration, growth, proliferation, and survival. Data from preclinical and phase $1 / 2$ clinical studies suggest that adding everolimus (an oral mTOR inhibitor) to trastuzumab plus chemotherapy may enhance the efficacy of, and restore
\end{abstract}

Presented at 2010 ASCO annual meeting; abstract published as Dalenc F, et al. J Clin Oncol. 2010; 28(May 20 suppl), Abstract 1013.

\section{S. A. Hurvitz $(\square)$}

Department of Medicine, Hematology/Oncology, UCLA Jonsson Comprehensive Cancer Center, 10945 Le Conte Avenue, PVUB

Suite 3360, Los Angeles, CA 90095, USA

e-mail: shurvitz@mednet.ucla.edu

F. Dalenc

Institut Claudius Regaud, Toulouse, France

\section{Campone}

Centre René Gauducheau, Nantes-Saint-Herblain, France

\section{R. M. O'Regan}

Department of Hematology and Medical Oncology, Winship

Cancer Institute of Emory University, Atlanta, GA, USA

\section{C. Tjan-Heijnen}

Department of Medical Oncology, Maastricht University

Medical Centre, Maastricht, The Netherlands

\section{J. Gligorov}

Medical Oncology Department, APHP-IUC, APREC, Paris,

France

\section{A. Llombart}

Oncology Service, Hospital Universitario Arnau de Vilanova,

Lleida, Spain sensitivity to, trastuzumab-based therapy. In this phase 2 multicenter study, adult patients with HER2-positive advanced breast cancer resistant to trastuzumab and pretreated with a taxane received everolimus $10 \mathrm{mg} /$ day in combination with paclitaxel $\left(80 \mathrm{mg} / \mathrm{m}^{2}\right.$ days 1,8 , and 15 every 4 weeks) and trastuzumab ( $4 \mathrm{mg} / \mathrm{kg}$ loading dose followed by $2 \mathrm{mg} / \mathrm{kg}$ weekly), administered in 28-day cycles. Endpoints included overall response rate (ORR), progression-free survival (PFS), overall survival (OS), and safety. Fifty-five patients were enrolled; one remained on study treatment at the time of data

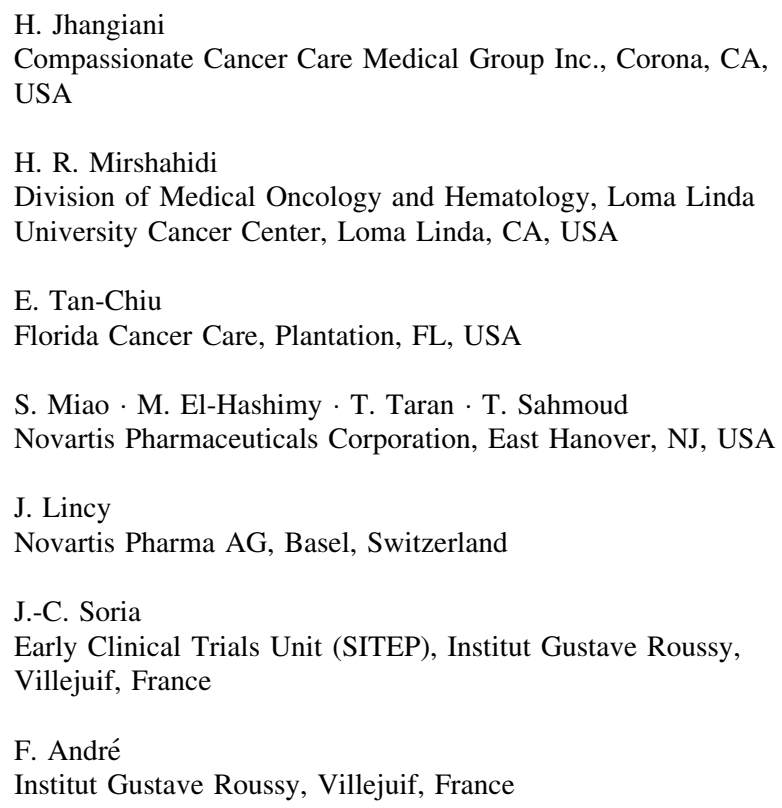


cutoff. The median number of prior chemotherapy lines for advanced disease was 3.5 (range 1-11). The ORR was $21.8 \%$, the clinical benefit rate was $36.4 \%$, the median PFS estimate was 5.5 months $(95 \%$ confidence interval [CI]: 4.99-7.69 months), and the median OS estimate was 18.1 months (95\% CI: 12.85-24.11 months). Hematologic grade $3 / 4$ adverse events (AEs) included neutropenia $(25.5 \%$ grade $3,3.6 \%$ grade 4$)$, anemia $(7.3 \%$ grade 3$)$, and thrombocytopenia $(5.5 \%$ grade $3,1.8 \%$ grade 4$)$. Nonhematologic grade 3/4 AEs included stomatitis (20.0\%), diarrhea $(5.5 \%)$, vomiting $(5.5 \%)$, fatigue $(5.5 \%)$, and pneumonia $(5.5 \%)$, all grade 3 . These findings suggest that the combination of everolimus plus trastuzumab and paclitaxel is feasible, with promising activity in patients with highly resistant HER2-positive advanced breast cancer. This combination is currently under investigation in the BOLERO-1 phase 3 trial.

Keywords Advanced breast cancer - Everolimus . Human epidermal growth factor receptor 2-positive . mTOR inhibitor . Paclitaxel - Trastuzumab resistant

$\begin{array}{ll}\text { Abbreviations } \\ \text { AE } & \text { Adverse event } \\ \text { Akt } & \text { Protein kinase B } \\ \text { CBR } & \text { Clinical benefit rate } \\ \text { CI } & \text { Confidence interval } \\ \text { CT } & \text { Computed tomography } \\ \text { DLCO } & \text { Carbon monoxide diffusing capacity } \\ \text { HER2 } & \text { Human epidermal growth factor receptor-2 } \\ \text { mTOR } & \text { Mammalian target of rapamycin } \\ \text { ORR } & \text { Overall response rate } \\ \text { OS } & \text { Overall survival } \\ \text { PFS } & \text { Progression-free survival } \\ \text { PI3K } & \text { Phosphatidylinositol 3-kinase } \\ \text { PTEN } & \text { Phosphatase and tensin } \\ \text { RECIST } & \text { Response evaluation criteria in solid tumors } \\ \text { T } & \text { Paclitaxel } \\ \text { TRAS } & \text { Trastuzumab } \\ \text { WHO } & \text { World Health Organization }\end{array}$

\section{Introduction}

Overexpression of the tyrosine kinase human epidermal growth factor receptor-2 (HER2) due to amplification of the $H E R 2 /$ neu proto-oncogene is reported in nearly $25 \%$ of all breast cancers and is associated with aggressive breast cancer cell growth $[1,2]$. In clinical practice, HER2 protein overexpression or amplification is linked to poor prognosis, increased risk of metastases, reduced diseasefree survival, and increased mortality [3, 4]. Agents that target HER2, such as trastuzumab, pertuzumab, T-DM1, and lapatinib, have been shown to improve clinical outcomes in patients with HER2-positive breast cancer via down-regulation or inhibition of HER2 activity [5-7]. Trastuzumab, which targets the extracellular domain of HER2, has become the cornerstone of combination therapies for HER2-positive early and advanced breast cancer based on the results of numerous clinical trials [6, 8, 9].

Despite the success of these HER2-directed therapies, the majority of patients with advanced breast cancer relapse or progress [10]. Resistance to trastuzumab is a major clinical concern with room for improvement, considering that the response rates to initial trastuzumab treatment range between 33 and $50 \%$ in patients with HER2-positive advanced breast cancer $[11,12]$. In addition, $70 \%$ of patients with initial response to trastuzumab treatment experience disease progression within 1 year [13]. Therefore, additional treatment options are needed to effectively manage HER2-positive advanced breast cancer. Trastuzumab resistance is hypothesized to occur via a number of mechanisms, including increased signaling mediated by upstream growth factor receptors, alterations of the HER2 receptor, phosphatase and tensin (PTEN) deficiency, and constitutive activation of phosphatidylinositol 3-kinase (PI3K) [3, 5, 13].

Increased activation of the PI3K/protein kinase B (Akt)/ mammalian target of rapamycin (mTOR) pathway results in dysregulation of cell migration, growth, proliferation, and survival [14]. Therefore, agents that inhibit the PI3K/ Akt/mTOR pathway may restore sensitivity to trastuzumab-based therapy. This hypothesis is supported by preclinical studies in which PI3K inhibitors overcame PTEN loss-induced trastuzumab resistance and slowed the growth of HER2-positive breast cancer cells in vitro and in vivo $[15,16]$.

Everolimus is an oral mTOR inhibitor approved for several oncology indications, including the treatment of patients with hormone-receptor-positive advanced breast cancer recurring or progressing during or after treatment with nonsteroidal aromatase inhibitors [17, 18]. A phase 1b/2 study was conducted in patients with taxane-pretreated and trastuzumab-resistant HER2-positive advanced breast cancer to determine the optimal dose and schedule of everolimus in combination with weekly trastuzumab and paclitaxel. The phase $1 \mathrm{~b}$ portion of the study reported encouraging antitumor activity and generally good tolerability when everolimus ( $5 \mathrm{mg} /$ day, $10 \mathrm{mg} / \mathrm{day}$, or $30 \mathrm{mg} /$ week) was combined with weekly trastuzumab and paclitaxel [19]. The overall response rate (ORR) was $44 \%$, and median progression-free survival (PFS) was approximately 8 months. The current report from the phase 2 portion of this study provides further insights into the efficacy and safety of daily everolimus $(10 \mathrm{mg})$ in combination with weekly paclitaxel and trastuzumab in patients with trastuzumab-resistant HER2-positive advanced breast cancer. 


\section{Patients and methods}

Study design and patients

J2101 was an open-label, multicenter, phase 2 study with a Simon 2-stage design, involving patients with HER2positive advanced breast cancer whose disease progressed on or after trastuzumab and taxane therapy. The Simon 2 -stage design was considered optimal to allow for early termination of the study after stage 1 in case of lack of efficacy. In the first stage, 30 patients were to be enrolled. If two or more patients achieved a response in the first stage, an additional 22 patients were to be enrolled; otherwise, the study was to be stopped.

Adult patients ( $\geq 18$ years of age) with histologically confirmed HER2-positive advanced breast cancer (immunohistochemistry $3^{+}$or positive fluorescence in situ hybridization) whose disease progressed during or within 3 months of receiving the last dose of trastuzumab for advanced disease or recurred within 12 months of completing trastuzumab-based (neo)adjuvant therapy were eligible to enroll. In addition, patients were required to have experienced disease progression during or within 6 months of the last taxane dose (with or without documented response) for advanced disease, or recurrence within 12 months of completing taxane-based chemotherapy as (neo)adjuvant therapy. Other eligibility criteria included a World Health Organization (WHO) performance status of 0 or 1 , measurable disease according to response evaluation criteria in solid tumors (RECIST) 1.0, left ventricular ejection fraction greater than $50 \%$, and adequate bone marrow, liver, and renal function. Exclusion criteria included uncontrolled or symptomatic central nervous system metastases; prior chemotherapy, immunotherapy, or radiotherapy within 4 weeks or prior lapatinib within 2 weeks of study entry; prior treatment with endocrine therapy for breast cancer (endocrine therapy had to have either failed in patients with hormone-receptor-positive disease within 2 weeks of randomization or patients had to be deemed unsuitable for endocrine therapy); or previous exposure to mTOR inhibitors.

All patients provided written informed consent before registration. The J2101 study was conducted in accordance with the Declaration of Helsinki and with local ethics committee approval at each participating center (16 centers in Belgium, France, The Netherlands, Spain, and the United States).

\section{Treatment}

For the current single-arm phase 2 study, enrolled patients received daily oral everolimus $10 \mathrm{mg}$ plus weekly trastuzumab and paclitaxel administered in 28-day cycles. The
$10 \mathrm{mg} /$ day dose of everolimus used was determined based on the efficacy and safety findings in the 3 -arm phase $1 \mathrm{~b}$ dose-escalation portion of this study, in which two daily regimens ( 5 and $10 \mathrm{mg} /$ day) and 1 weekly regimen (30 mg/week) were examined [19]. Among these, everolimus $10 \mathrm{mg} /$ day was chosen for further development on the basis of observed dose-limiting toxicity (grade 1/2 stomatitis at the end of cycle 1) and overall safety.

In addition to daily everolimus, all patients in this phase 2 study received weekly trastuzumab and paclitaxel infusion $\left(80 \mathrm{mg} / \mathrm{m}^{2}\right.$ on days 1,8 , and 15 of each cycle for at least six cycles). Trastuzumab was administered intravenously at a loading dose of $4 \mathrm{mg} / \mathrm{kg}$ on day 1 of cycle 1 , with a maintenance dose of $2 \mathrm{mg} / \mathrm{kg}$ thereafter. Following completion of the first six cycles, patients continued to receive everolimus and trastuzumab, while continuation of paclitaxel was allowed at the investigator's discretion. For those patients who did not continue paclitaxel beyond the first six cycles, trastuzumab was administered once every 3 weeks at a dose of $6 \mathrm{mg} / \mathrm{kg}$. Patients could receive everolimus alone (if trastuzumab was discontinued early because of toxicity) or with trastuzumab until disease progression or unacceptable toxicity occurred.

In addition to the study treatments, prophylactic use of antiemetics was recommended. Patients were allowed to continue baseline bisphosphonate or analgesic therapy. In the event of documented cytopenia (after the first cycle of treatment), the use of hematopoietic growth factors was permitted.

\section{Study objectives}

The primary endpoint of the study was ORR as assessed by RECIST 1.0. Secondary endpoints included PFS, overall survival (OS), clinical benefit rate (CBR), and safety.

\section{Study assessments}

All baseline assessments were obtained at visit 1 (within 3 weeks before start of treatment). These evaluations included physical and neurologic examinations, WHO performance status, vital signs, height, weight, electrocardiogram, chest $\mathrm{X}$-ray, cardiac imaging, pulmonary function tests, demographics, medical history, confirmation of HER2-positive metastatic breast cancer diagnosis, extent of cancer, documentations of prior therapy, tumor assessment, laboratory evaluations, and a pregnancy test.

\section{Assessment of clinical response}

Radiologic assessments (computed tomography [CT] scan, magnetic resonance imaging) and/or physical examination 
were performed every 8 weeks during the first six cycles of study treatment. Patients continuing on everolimus and trastuzumab beyond the first six cycles had radiologic assessments performed every 9 weeks (every 8 weeks if paclitaxel was continued) until disease progression or study discontinuation for any other reason.

\section{Assessment of safety}

Adverse events (AEs) and laboratory assessments for safety were evaluated throughout the study. AEs were assessed according to National Cancer Institute/National Institutes of Health Common Terminology Criteria for AEs, version 3.0. Cardiac imaging (multigated angiogram or echocardiogram) and electrocardiograms were repeated every 12 weeks (or as clinically indicated). Chest X-rays were performed every two cycles and, if clinically indicated, chest CT scans were performed to monitor for interstitial pneumonitis. Pulmonary function tests (spirometry, carbon monoxide diffusing capacity [DLCO], and room air oxygen saturation at rest) were performed at baseline and on suspicion of noninfectious pneumonitis.

Everolimus dose interruptions and/or reductions were allowed for specific AEs such as grade 2/3 pneumonitis, grade $\geq 2$ neurotoxicity, and grade $\geq 3$ AEs (except hyperlipidemia and hyperglycemia) until the AE resolved to grade $\leq 1$. If necessary, the everolimus dose was reduced from 10 to $5 \mathrm{mg} /$ day or from 5 to $2.5 \mathrm{mg} /$ day. The dose of paclitaxel could be reduced by $10 \mathrm{mg} / \mathrm{m}^{2}$ (for grade $\geq 2$ pneumonitis or other intolerable grade $\geq 2$ AEs except neurotoxicity) or by $20 \mathrm{mg} / \mathrm{m}^{2}$ (for hematologic toxicities or grade $\geq 2$ neurotoxicity) if dose interruption did not result in AE resolution to grade $\leq 1$. No dose reductions were allowed for trastuzumab; however, dose interruption was permitted to control infusion-related symptoms and for AEs such as a decrease in left ventricular ejection fraction of $\geq 10$ points from baseline or $<50 \%$, or development of grade $\geq 3$ pneumonitis. Treatment discontinuation was recommended for any toxicity requiring interruption for more than 3 weeks and was required for grade 4 pneumonitis.

\section{Statistical analysis}

The Simon 2-stage analysis was based on the intent-to-treat population and was designed with $80 \%$ power to reject the null hypothesis when the true response rate is $15 \%$. Overall response rates are presented with exact 2-sided $95 \%$ confidence interval (CI), as determined via the Clopper-Pearson method. PFS and OS were estimated using the Kaplan-Meier method and are presented with the 2-sided $95 \%$ CI.

\section{Results}

Patients

A total of 55 women were enrolled from February to November 2009. The median age of patients enrolled was 56 years, and $83.6 \%$ of the patients were under 65 years of age. Sixty-six percent had a WHO performance status of 0 and $78 \%$ had visceral disease. These patients were heavily pretreated, with a median of 3.5 prior lines of chemotherapy for metastatic disease. All patients had previously received trastuzumab and taxane; $40(73 \%)$ and $35(64 \%)$ patients had received prior anthracycline or lapatinib, respectively. Resistance to trastuzumab was documented in $52(95 \%)$ patients; resistance to taxane or lapatinib was reported in $40(73 \%)$ and $33(60 \%)$ patients, respectively (Table 1).

Of the 55 patients enrolled in the study, 28 (50.9\%) completed six cycles of treatment, and 24 of these patients continued study treatment beyond six cycles (Table 2). At the cutoff date (March 15, 2012), one patient was still receiving study treatment. Among the 55 enrolled patients, $37(67.3 \%)$ discontinued treatment due to progressive disease: $16(29.1 \%)$ patients during the first six cycles and 21 patients who continued treatment beyond the first six cycles. A total of 10 patients discontinued study treatment because of AEs; eight of these patients discontinued during the first six cycles of study treatment. AEs resulting in discontinuation from the study during the first six cycles included ascites and general physical health deterioration $(n=1)$; decreased performance status and fatigue $(n=1)$; febrile neutropenia and sepsis $(n=1)$; decreased total lung capacity and lung disorder $(n=1)$; and pneumonitis, pneumonia, interstitial lung disease, and decreased DLCO ( $n=1$ each). Two patients discontinued treatment because of AEs after the first six cycles: brain edema $(n=1)$ and decreased forced expiratory volume and dysphonia $(n=1)$. Most of these AEs were suspected to be related to study treatment.

The median duration of exposure to both everolimus and trastuzumab was 24.0 weeks, whereas the median duration of exposure to paclitaxel was 21.7 weeks (Table 3). Patients were followed for a median of 32.6 months (median treatment start date to data cutoff date). The median dose intensity of everolimus was $8.75 \mathrm{mg} /$ day; median dose intensities of trastuzumab and paclitaxel were 0.29 and $7.09 \mathrm{mg} /$ day, respectively (Table 3). The relative dose intensities of everolimus, trastuzumab, and paclitaxel were $0.88,1.00$, and 0.83 , respectively. Overall, 47.3 and $89.1 \%$ of patients required at least one dose reduction or interruption of any study drug, respectively (Table 3). The proportions of patients requiring at least one dose reduction were $34.5 \%$ for everolimus (30.9\% for AEs), $25.5 \%$ for 
Table 1 Demographic and baseline disease characteristics of patients

\begin{tabular}{|c|c|}
\hline & $\begin{array}{l}\text { Everolimus }+ \text { trastuzumab }+ \\
\text { paclitaxel }(N=55)\end{array}$ \\
\hline \multicolumn{2}{|l|}{ Age, years } \\
\hline Median (range) & $56.0(31-83)$ \\
\hline \multicolumn{2}{|l|}{ Age, $n(\%)$} \\
\hline$<65$ years & $46(83.6)$ \\
\hline$\geq 65$ years & $9(16.4)$ \\
\hline \multicolumn{2}{|c|}{ WHO performance status, $n(\%)$} \\
\hline 0 & $36(65.5)$ \\
\hline 1 & $19(34.5)$ \\
\hline \multicolumn{2}{|l|}{ Predominant race, $n(\%)$} \\
\hline Caucasian & $48(87.3)$ \\
\hline Black & $4(7.3)$ \\
\hline Asian & 0 \\
\hline Native American & 0 \\
\hline Pacific Islander & 0 \\
\hline Other & $3(5.5)$ \\
\hline \multicolumn{2}{|l|}{ Visceral disease, $n(\%)$} \\
\hline Any & $43(78.2)$ \\
\hline Lung & $24(43.6)$ \\
\hline Liver & $29(52.7)$ \\
\hline \multicolumn{2}{|l|}{ Target lesions, $n(\%)$} \\
\hline Yes & $52(94.5)$ \\
\hline No & $3(5.5)$ \\
\hline \multicolumn{2}{|c|}{ Current stage of cancer, $n(\%)$} \\
\hline IV & $55(100)$ \\
\hline Disease-free interval, $n^{\mathrm{a}}$ & 32 \\
\hline Median weeks (range) & $108.9(3-439)$ \\
\hline \multicolumn{2}{|c|}{$\begin{array}{l}\text { Number of previous chemotherapy } \\
\text { lines for advanced disease }\end{array}$} \\
\hline Median (range) & $3.5(1-11)$ \\
\hline \multicolumn{2}{|l|}{$\begin{array}{l}\text { Pretreatment for advanced } \\
\text { disease, } n(\%)\end{array}$} \\
\hline Trastuzumab & $55(100.0)$ \\
\hline Taxane & $55(100.0)$ \\
\hline Lapatinib & $35(63.6)$ \\
\hline Anthracycline & $40(72.7)$ \\
\hline \multicolumn{2}{|l|}{ Resistance, $n(\%)$} \\
\hline Trastuzumab & $52(94.5)$ \\
\hline Taxane & $40(72.7)$ \\
\hline Lapatinib & $33\left(\begin{array}{lll}60 & 0\end{array}\right)$ \\
\hline
\end{tabular}

WHO World Health Organization

a Disease-free interval is calculated as the interval between date of first surgery with no residual disease and date of first recurrence of disease

paclitaxel (21.8\% for AEs), and none for trastuzumab per protocol. At least one everolimus dose interruption was required for $70.9 \%$ of patients (61.8\% for AEs), $67.3 \%$ of patients required a paclitaxel dose interruption $(65.5 \%$
Table 2 Patient disposition (full analysis set; $N=55$ )

Everolimus + trastuzumab + paclitaxel, $n(\%)$

$\begin{array}{lc}\text { First six cycles } & \\ \text { Enrolled } & 55(100) \\ \text { Completed six cycles } & 28(50.9) \\ \text { Continued beyond six cycles }{ }^{\mathrm{a}} & 24(43.6) \\ \text { Discontinued } & 27(49.1) \\ \text { Disease progression } & 16(29.1) \\ \text { Adverse events(s) } & 8(14.5) \\ \text { Patient withdrew consent } & 3(5.5) \\ \text { Continued beyond six cycles } & \text { b } \\ \text { Beyond first six cycles } & 0 \\ \text { Continued beyond six cycles } & 24 \\ \text { Ongoing } & 1 \\ \text { Discontinued } & 23 \\ \text { Disease progression } & 21 \\ \text { Adverse event(s) } & 2\end{array}$

${ }^{a}$ Percentage of patients continuing beyond six cycles who completed first six cycles

b Percentage of patients continuing beyond six cycles who discontinued during first six cycles

for AEs), and $45.5 \%$ of patients required a trastuzumab dose interruption ( $34.5 \%$ for AEs).

Clinical activity

The trial met its primary endpoint with 12 partial responses, resulting in an ORR of $21.8 \%$ (Table 4). Disease stabilization was achieved in $26(47.3 \%)$ patients, whereas eight $(14.5 \%)$ patients had progressive disease. The disease control rate (defined as ORR plus stable disease) was $69.1 \%$ and the CBR (defined as ORR plus stable disease lasting 24 weeks or longer) was $36.4 \%$. Overall, at the time of data cutoff, there were 36 PFS events (34 progressive disease and two deaths) based on local radiology review, and the median PFS estimate was 5.5 months (95 \% CI: 4.99-7.69 months; Fig. 1). The median OS estimate since start of the study was 18.1 months (95\% CI: 12.85-24.11 months; Fig. 2).

\section{Tolerability}

The incidences of AEs were consistent with the known safety profiles of the study drugs (Table 5). All 55 patients reported AEs while on study treatment. Of these, 48 patients $(87.3 \%)$ experienced grade 3/4 AEs, 26 patients (47.3\%) had serious AEs, and 16 patients $(29.1 \%)$ had AEs leading to discontinuation of at least one of the study treatments. Three deaths occurred on treatment (during study treatment or within 28 days of last treatment): two 
Table 3 Treatment characteristics (safety population; $N=55$ )

\begin{tabular}{llll}
\hline & Everolimus & Trastuzumab & Paclitaxel \\
\hline Mean total dose, mg (SD) & $1045.5(541.56)$ & $37.2(13.96)$ & $906.7(415.78)$ \\
Median duration of exposure, weeks & $24.00^{\mathrm{a}}$ & $24.00^{\mathrm{a}}$ & $21.71^{\mathrm{a}}$ \\
Range & $1.7-122.7$ & $2.0-95.0$ & $2.7-68.0$ \\
Mean dose intensity, mg/day (SD) & $7.69(2.243)$ & $0.28(0.027)$ & $6.85(1.536)$ \\
Median dose intensity, mg/day & 8.75 & 0.29 & 7.09 \\
Range & $3.4-10.0$ & $0.2-0.3$ & $2.5-8.8$ \\
Median relative dose intensity ${ }^{\mathrm{c}}$ & 0.875 & 1.003 & 0.827 \\
Range & $0.34-1.00$ & $0.69-1.19$ & $0.30-1.02$ \\
$\geq 1$ Dose reduction, $n(\%)$ & $19(34.5)$ & 0 & $14(25.5)$ \\
$\geq 1$ Dose interruption, $n(\%)$ & $39(70.9)$ & $25(45.5)$ & $37(67.3)$ \\
\hline
\end{tabular}

$S D$ standard deviation

${ }^{\text {a }}$ Duration of exposure (weeks) $=$ (date of last dose $+X-$ date of first dose +1 )/7, where $X$ is the number of days remaining to complete the exposure time of the last dose

${ }^{\mathrm{b}}$ Duration of exposure for combination treatment (weeks) $=$ date of last dose $+X-$ date of first dose +1 )/7, where $X$ is the number of days remaining to complete the exposure time of the last dose

${ }^{c}$ Relative dose intensity $=$ dose intensity/planned dose intensity

Table 4 Best overall response (full analysis set; $N=55$ )

\begin{tabular}{ll}
\hline & $\begin{array}{l}\text { Everolimus }+ \text { trastuzumab }+ \\
\text { paclitaxel }\end{array}$ \\
\hline $\begin{array}{l}\text { Best overall response, } n(\%) \\
\text { Complete }\end{array}$ & 0 \\
Partial & $12(21.8)$ \\
Stable disease & $26(47.3)$ \\
Progressive disease & $8(14.5)$ \\
Unknown & $9(16.4)$ \\
Overall response rate, $n(\%)^{\mathrm{a}}$ & $12(21.8)$ \\
$95 \%$ CI & $11.8-35.0$ \\
Disease control rate, $n(\%)^{\mathrm{b}}$ & $38(69.1)$ \\
95\% CI & $55.2-80.9$ \\
Clinical benefit rate, $n(\%)^{\mathrm{c}}$ & $20(36.4)$ \\
$95 \%$ CI & $23.8-50.4$ \\
\hline
\end{tabular}

${ }^{a}$ Complete and partial responses

b Complete and partial responses plus stable disease

${ }^{c}$ Complete and partial responses plus stable disease $\geq 24$ weeks

were attributable to disease progression and one to sepsis (suspected by the investigator to be related to study drug). The most common AEs were stomatitis (76.4\%), diarrhea $(56.4 \%)$, asthenia $(50.9 \%)$, rash $(47.3 \%)$, headache $(43.6 \%)$, and pyrexia (40.0\%). The most common grade $3 / 4$ AEs (regardless of study treatment) reported in at least $5 \%$ of patients were neutropenia, stomatitis, lymphopenia, leukopenia, anemia, thrombocytopenia, diarrhea, vomiting, fatigue, and pneumonia.

Most of the clinically notable AEs associated with everolimus were grade 1 or 2 ; among those that were grade 3 or 4 , most were manageable by dose adjustments and/or

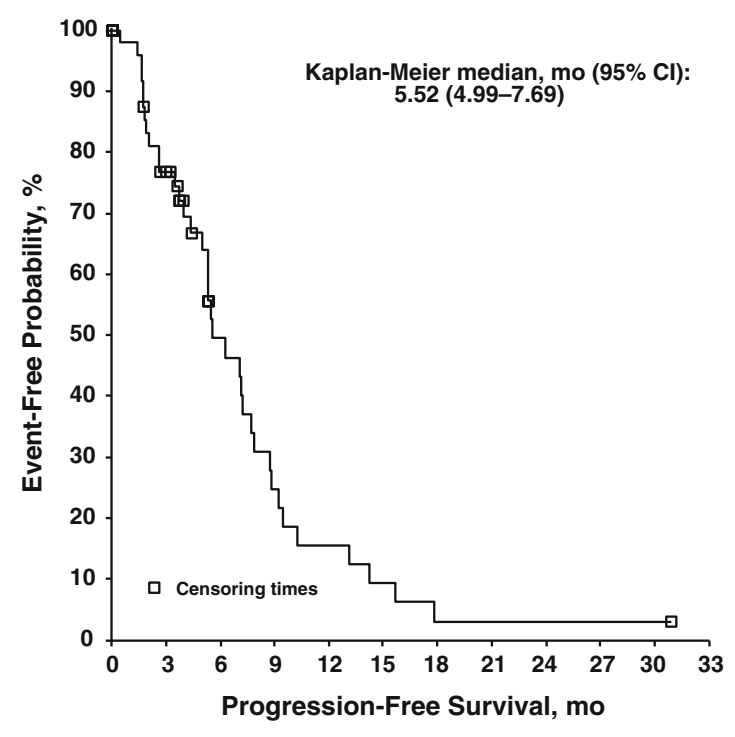

Number of patients still at risk

$\begin{array}{llllllllllll}\text { EVE + TRAS + T } 55 & 34 & 16 & 8 & 5 & 2 & 1 & 1 & 1 & 1 & 1 & -\end{array}$

Fig. 1 Kaplan-Meier analyses of progression-free survival in patients with human epidermal growth factor receptor-2-positive advanced breast cancer treated with everolimus ( $E V E)$, trastuzumab (TRAS), and paclitaxel (T). CI confidence interval

concomitant medications. Cytopenias were reported in 30 $(54.5 \%)$ patients and were suspected to be related to study treatment; these were mostly managed by dose interruption and/or dose reduction. Only one patient discontinued paclitaxel early due to thrombocytopenia. Stomatitis, the most frequently reported nonhematologic, clinically notable AE, was primarily grade $1 / 2(56.4 \%)$ and the remainder grade $3(20 \%)$. None of these patients discontinued study 


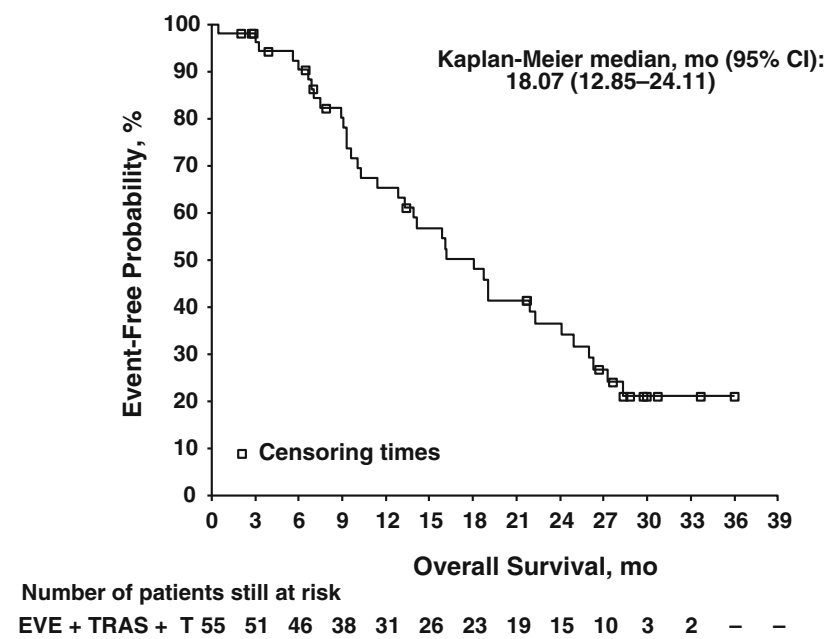

Fig. 2 Kaplan-Meier analyses of overall survival in patients with human epidermal growth factor receptor-2-positive advanced breast cancer treated with everolimus (EVE), trastuzumab (TRAS), and paclitaxel (T). CI confidence interval

treatment due to stomatitis, and all 11 patients who experienced grade 3 stomatitis were brought to complete resolution with dose interruption and/or dose reduction, along with concomitant medication. Noninfectious pneumonitis (including interstitial lung disease) was reported in 4 (7.3\%) patients. Grade 2 noninfectious pneumonitis events were diagnosed in two patients and resolved completely following dose interruption and dose reduction; grade 3 events were diagnosed in two patients and resulted in study treatment discontinuation. Both patients who discontinued were treated with steroid therapy and supplemental oxygen; one event resolved 20 days after last study treatment, and one was ongoing at the time of the last available report. No grade 4 noninfectious pneumonitis events were reported (Table 5).

Of the concomitant treatments allowed on study, hematopoietic growth factors were used in $7.2 \%$ of patients who had documented cytopenia during/after cycle 1; baseline bisphosphonate treatment and analgesic medication (including opioids) were continued in 5.4 and $25.4 \%$ of patients, respectively. Use of prophylactic antiemetic medications was continued from baseline in $5.4 \%$ of patients.

\section{Discussion}

The results from this phase 2 study provide additional clinical support for the use of mTOR inhibitors to improve the benefit of trastuzumab-based treatment strategies in women with HER2-positive advanced breast cancer. In this study, everolimus added to weekly trastuzumab and paclitaxel
Table 5 Adverse events irrespective of relation to study treatment with $\geq 10 \%$ incidence (any grade) or $\geq 5 \%$ incidence (grade 3 or 4 )

\begin{tabular}{|c|c|c|c|c|}
\hline \multirow[t]{2}{*}{ Adverse event $(\%)^{\mathrm{a}}$} & \multicolumn{4}{|c|}{$\begin{array}{l}\text { Everolimus }+ \text { trastuzumab }+ \text { paclitaxel } \\
(N=55)\end{array}$} \\
\hline & Grade 1 & Grade 2 & Grade 3 & Grade 4 \\
\hline \multicolumn{5}{|l|}{ Hematologic disorders } \\
\hline Neutropenia & 0 & 7.3 & 25.5 & 3.6 \\
\hline Anemia & 7.3 & 20.0 & 7.3 & 0 \\
\hline Leukopenia & 0 & 3.6 & 16.4 & 1.8 \\
\hline Lymphopenia & 0 & 0 & 18.2 & 1.8 \\
\hline Thrombocytopenia & 1.8 & 9.1 & 5.5 & 1.8 \\
\hline \multicolumn{5}{|l|}{ Nonhematologic disorders } \\
\hline Stomatitis & 23.6 & 32.7 & 20.0 & 0 \\
\hline Diarrhea & 34.5 & 16.4 & 5.5 & 0 \\
\hline Asthenia & 20.0 & 27.3 & 3.6 & 0 \\
\hline Rash & 27.3 & 18.2 & 1.8 & 0 \\
\hline Headache & 27.3 & 14.5 & 1.8 & 0 \\
\hline Pyrexia & 21.8 & 16.4 & 0 & 1.8 \\
\hline Nausea & 20.0 & 18.2 & 0 & 0 \\
\hline Cough & 23.6 & 12.7 & 0 & 0 \\
\hline Peripheral neuropathy & 27.3 & 5.5 & 3.6 & 0 \\
\hline Epistaxis & 27.3 & 1.8 & 0 & 0 \\
\hline Vomiting & 12.7 & 9.1 & 5.5 & 0 \\
\hline Constipation & 21.8 & 1.8 & 0 & 0 \\
\hline Peripheral edema & 18.2 & 5.5 & 0 & 0 \\
\hline Fatigue & 9.1 & 7.3 & 5.5 & 0 \\
\hline Arthralgia & 10.9 & 9.1 & 0 & 0 \\
\hline Nasopharyngitis & 10.9 & 7.3 & 0 & 0 \\
\hline Erythema & 10.9 & 7.3 & 0 & 0 \\
\hline Decreased appetite & 10.9 & 7.3 & 0 & 0 \\
\hline Myalgia & 14.5 & 3.6 & 0 & 0 \\
\hline Dyspnea & 10.9 & 5.5 & 0 & 0 \\
\hline Muscle spasms & 12.7 & 1.8 & 0 & 0 \\
\hline Dry skin & 10.9 & 0 & 0 & 0 \\
\hline Insomnia & 10.9 & 0 & 0 & 0 \\
\hline Hypophosphatemia & 0 & 0 & 5.5 & 1.8 \\
\hline Pneumonia & 0 & 0 & 5.5 & 0 \\
\hline
\end{tabular}

The safety analyses excluded events that occurred $>28$ days after last dose of study treatment

a A patient with multiple occurrences of an adverse event was counted only once in the adverse event category. A patient with multiple severity ratings for an adverse event was only included under the maximum rating

yielded a $22 \%$ ORR and $36 \%$ CBR in heavily pretreated patients with tumors exhibiting resistance to trastuzumab (defined as disease progression within 3 months of their last trastuzumab-containing regimen for advanced cancer, or within 12 months after neo/adjuvant therapy). The median PFS of 5.5 months was also encouraging given that the majority of patients had progressed within 3 months of their last regimen for advanced disease. In addition, the median 
OS of 18 months was similar to the 23 months reported in a phase 2 study of weekly trastuzumab and paclitaxel in heavily pretreated patients (two or more prior lines of chemotherapy) with trastuzumab-sensitive advanced HER2positive breast cancer (i.e., no prior exposure to trastuzumab) [20].

Data from primary breast tumors suggest a causal relationship between PI3K/Akt/mTOR pathway activation and overexpression of HER2, implicating the pathway in progression of HER2-positive breast cancer [21]. These findings led to the examination of mTOR inhibition as a strategy for improving sensitivity to trastuzumab-based therapy [22]. This approach was found to be effective in overcoming resistance to trastuzumab as well as in restoring lapatinib sensitivity in several preclinical models of HER2-positive breast cancer [15, 16, 23, 24]. Moreover, in prospective data collected from patients with trastuzumab-refractory breast cancer, loss of HER2 overexpression was rare, whereas activation of the PI3K/Akt/ mTOR pathway through loss of PTEN or PIK3CA mutation was frequently observed. Interestingly, a recent biomarker analysis from the phase 3 CLEOPATRA study of pertuzumab in combination with trastuzumab and docetaxel showed that PIK3CA mutations were associated with a poor prognosis in patients with HER2-positive advanced breast cancer in $[25,26]$. However, this analysis did not identify any predictive markers (other than HER2) for response to anti-HER2 therapy; i.e., these biomarker analyses did not provide any insight that would allow refinement of the HER2-positive target population treated with this drug regimen [26]. Analysis of potential biomarkers (e.g., PTEN, HER2, and PI3K) that might predict benefit from everolimus is beyond the scope of the current phase 2 trial because of its small sample size. However, these biomarkers are currently being analyzed in a large, randomized, phase 3 trial of everolimus plus trastuzumab in combination with paclitaxel (BOLERO-1), and this trial may provide future insights into selecting the appropriate patient population to treat with everolimus in combination with available HER2-targeting agents.

Previously reported studies provide further support for the activity of everolimus when combined with trastuzumab in heavily pretreated patients with HER2-positive advanced breast cancer. In the 3-arm phase 1 dose-escalation portion of this study, the ORR was $44 \%$ in 27 evaluable patients from the whole study population and was $31 \%$ among 13 patients who received $10 \mathrm{mg} /$ day everolimus [19]. Likewise, another phase 1/2 study of everolimus in combination with weekly trastuzumab reported a CBR of $34 \%$ in a similar patient population with a high burden of visceral disease that had received at least two prior chemotherapy regimens for advanced breast cancer [27].
In the current study, most of the patients had received prior trastuzumab in the advanced setting and progressed within 3 months. Only seven patients had disease recurrence/progression within 12 months of completing (neo)adjuvant therapy. Therefore, the 5.5-month median PFS should be interpreted in the context of the patient population, which received a median of 3.5 prior lines of therapy, and the majority had progressed rapidly on or after their last trastuzumab-containing regimen for advanced disease. Notably, among 52 patients with tumors considered resistant to trastuzumab-based therapy, $29 \%$ had not progressed at a median follow-up of 32.6 months. Taken together, these data suggest that the combination of a HER2-independent anticancer agent, such as everolimus, with HER2-targeted treatment may delay disease progression in patients who develop trastuzumab-resistant disease. With respect to taxane resistance, $73 \%$ of eligible patients had resistant tumors, and seven patients experienced disease progression during or within 4 months of their last taxane-containing regimen. Thus, despite evidence of resistance to both trastuzumab and taxane therapy, clinical benefit was achieved with everolimus in combination with trastuzumab and paclitaxel.

Safety findings from the phase 2 portion of the trial were similar to observations during the phase 1 portion and consistent with the reported safety profile of each of the study drugs. No new safety signals were observed. As expected, stomatitis was the most frequently reported nonhematologic AE. By comparison, the most frequently reported AEs in the everolimus plus exemestane arm in the phase 3 BOLERO-2 study in hormone-receptor-positive advanced breast cancer were stomatitis, fatigue, asthenia, diarrhea, cough, pyrexia, and hyperglycemia. These are consistent with the AEs previously reported with everolimus monotherapy in other oncology indications [17, 2830]. Safety data from BOLERO-3, a phase 3 trial of everolimus and trastuzumab paired with vinorelbine instead of paclitaxel for the treatment of patients with HER2positive advanced breast cancer, revealed a very similar AE profile to that observed in the current phase 2 study. In the initial report from BOLERO-3, the most frequently reported nonhematologic AEs in the everolimus arm in BOLERO-3 were stomatitis, fatigue, pyrexia, diarrhea, nausea, and decreased appetite; commonly reported hematologic AEs for the everolimus arm were neutropenia, anemia, and leukopenia. The most common grade 3/4 nonhematologic AEs in the everolimus arm were stomatitis, fatigue, increased gamma-glutamyltransferase, and asthenia; common hematologic grade 3/4 AEs were neutropenia, leukopenia, anemia, and febrile neutropenia [31]. Overall, the nonhematologic AE profile of the combination of trastuzumab and vinorelbine with everolimus in the BOLERO-3 study was consistent with the known safety 
profiles of the individual drugs, and no new unexpected AEs were observed [31]. Final publication of the study outcomes is awaited.

In the current study, AEs were generally manageable with appropriate symptomatic treatment, dose interruptions and reductions, and implementation of the management guidelines per protocol, such as the introduction of hematopoietic growth factors in patients who experienced neutropenia in cycle 1. AEs prompted at least one dose reduction of everolimus in approximately one-third of patients and at least one everolimus dose interruption in $62 \%$ of patients. Similar proportions of patients required at least one paclitaxel dose interruption or reduction because of AEs. Notably, the most common AEs leading to discontinuation were lung-related AEs (six of ten patients who discontinued study treatment because of AEs). However, several patients had a history of underlying respiratory disorders at study entry such as exertional dyspnea, pneumothorax, and pulmonary embolism ( $n=1$ for each). Of the remaining four patients who discontinued study treatment because of AEs, two discontinued, in part, because of febrile neutropenia and brain edema, which have not been reported in breast cancer trials of everolimus in the absence of a chemotherapy partner [32]. For all patients, diligent screening as well as careful monitoring and appropriate dose modifications are recommended to maximize clinical benefit and minimize toxicity.

In conclusion, combining everolimus with trastuzumab and paclitaxel provided substantial clinical benefit in this heavily pretreated population of patients with HER2-positive advanced breast cancer who had progressed rapidly during or after their last treatment regimen, the majority of whom were resistant to trastuzumab and taxane treatment. The promising results achieved with this regimen are currently being confirmed in the randomized, phase 3, BOLERO-1 trial in the first-line setting.

Acknowledgments The J2101 trial was supported by Novartis Pharmaceuticals. We thank the patients, study site personnel, and the study team for their participation in the trial. Financial support for medical editorial assistance was provided by Novartis Pharmaceuticals. We thank Kristin E. Larsen, PhD, ProEd Communications, Inc., for medical editorial assistance with this manuscript.

Conflict of interest S. Hurvitz has received speaker travel reimbursement from Roche and Novartis. M. Campone has received remuneration from Novartis and reports a consultant/advisory role with Novartis-Servier. R.M. O'Regan reports a consultant/advisory role with Novartis and funding from Genentech. F. André reports a consultant/advisory role and funding from Novartis. J. Gligorov has received remuneration from Novartis and reports a consultant/advisory role with Roche. V.C. Tjan-Heijnen has received funding from Novartis, Amgen, Roche, and Sanofi-Aventis NL. H. Mirshahidi reports a consultant/advisory role with Genentech. F. Dalenc reports a consultant/advisory role with Novartis. J.-C. Soria and A. Llombart report no conflicts of interest. M. El-Hashimy is a Novartis employee and reports Novartis stock ownership. S. Miao, J. Lincy, T. Taran, and T. Sahmoud are Novartis employees.

Open Access This article is distributed under the terms of the Creative Commons Attribution Noncommercial License which permits any noncommercial use, distribution, and reproduction in any medium, provided the original author(s) and the source are credited.

\section{References}

1. Sauter G, Lee J, Bartlett JM, Slamon DJ, Press MF (2009) Guidelines for human epidermal growth factor receptor 2 testing: biologic and methodologic considerations. J Clin Oncol 27(8):1323-1333. doi:10.1200/JCO.2007.14.8197

2. Slamon DJ, Godolphin W, Jones LA, Holt JA, Wong SG, Keith DE, Levin WJ, Stuart SG, Udove J, Ullrich A et al (1989) Studies of the HER-2/neu proto-oncogene in human breast and ovarian cancer. Science 244(4905):707-712

3. Hurvitz SA, Hu Y, O’Brien N, Finn RS (2013) Current approaches and future directions in the treatment of HER2-positive breast cancer. Cancer Treat Rev 39(3):219-229. doi:10.1016/j. ctrv.2012.04.008

4. Ross JS, Slodkowska EA, Symmans WF, Pusztai L, Ravdin PM, Hortobagyi GN (2009) The HER-2 receptor and breast cancer: ten years of targeted anti-HER-2 therapy and personalized medicine. Oncologist 14(4):320-368. doi:10.1634/theoncologist. 2008-0230

5. Nahta R, O'Regan RM (2010) Evolving strategies for overcoming resistance to HER2-directed therapy: targeting the PI3K/Akt/ mTOR pathway. Clin Breast Cancer 10(Suppl 3):S72-S78. doi:10.3816/CBC.2010.s.015

6. Slamon DJ, Leyland-Jones B, Shak S, Fuchs H, Paton V, Bajamonde A, Fleming T, Eiermann W, Wolter J, Pegram M, Baselga J, Norton L (2001) Use of chemotherapy plus a monoclonal antibody against HER2 for metastatic breast cancer that overexpresses HER2. N Engl J Med 344(11):783-792

7. Hurvitz SA, Kakkar R (2012) The potential for trastuzumab emtansine in human epidermal growth factor receptor 2 positive metastatic breast cancer: latest evidence and ongoing studies. Ther Adv Med Oncol 4(5):235-245. doi:10.1177/1758834012451205

8. Vu T, Claret FX (2012) Trastuzumab: updated mechanisms of action and resistance in breast cancer. Front Oncol 2:62. doi:10. 3389/fonc. 2012.00062

9. Robert N, Leyland-Jones B, Asmar L, Belt R, Ilegbodu D, Loesch D, Raju R, Valentine E, Sayre R, Cobleigh M, Albain K, McCullough C, Fuchs L, Slamon D (2006) Randomized phase III study of trastuzumab, paclitaxel, and carboplatin compared with trastuzumab and paclitaxel in women with HER-2-overexpressing metastatic breast cancer. J Clin Oncol 24(18):2786-2792

10. Dent S, Verma S, Latreille J, Rayson D, Clemons M, Mackey J, Verma S, Lemieux J, Provencher L, Chia S, Wang B, Pritchard K (2009) The role of HER2-targeted therapies in women with HER2overexpressing metastatic breast cancer. Curr Oncol 16(4):25-35

11. Bartsch R, Wenzel C, Steger GG (2007) Trastuzumab in the management of early and advanced stage breast cancer. Biologics $1(1): 19-31$

12. Wong H, Leung R, Kwong A, Chiu J, Liang R, Swanton C, Yau T (2011) Integrating molecular mechanisms and clinical evidence in the management of trastuzumab resistant or refractory HER2(+) metastatic breast cancer. Oncologist 16(11):1535-1546. doi:10.1634/theoncologist.2011-0165 
13. Wong AL, Lee SC (2012) Mechanisms of resistance to trastuzumab and novel therapeutic strategies in HER2-positive breast cancer. Int J Breast Cancer 2012:415170. doi:10.1155/2012/ 415170

14. Vivanco I, Sawyers CL (2002) The phosphatidylinositol 3-Kinase AKT pathway in human cancer. Nat Rev Cancer 2(7):489-501

15. Lu CH, Wyszomierski SL, Tseng LM, Sun MH, Lan KH, Neal CL, Mills GB, Hortobagyi GN, Esteva FJ, Yu D (2007) Preclinical testing of clinically applicable strategies for overcoming trastuzumab resistance caused by PTEN deficiency. Clin Cancer Res 13(19):5883-5888

16. Nagata Y, Lan KH, Zhou X, Tan M, Esteva FJ, Sahin AA, Klos KS, Li P, Monia BP, Nguyen NT, Hortobagyi GN, Hung MC, Yu D (2004) PTEN activation contributes to tumor inhibition by trastuzumab, and loss of PTEN predicts trastuzumab resistance in patients. Cancer Cell 6(2):117-127

17. Baselga J, Campone M, Piccart M, Burris HA 3rd, Rugo HS, Sahmoud T, Noguchi S, Gnant M, Pritchard KI, Lebrun F, Beck JT, Ito Y, Yardley D, Deleu I, Perez A, Bachelot T, Vittori L, Xu Z, Mukhopadhyay P, Lebwohl D, Hortobagyi GN (2012) Everolimus in postmenopausal hormone-receptor-positive advanced breast cancer. N Engl J Med 366(6):520-529. doi:10.1056/ NEJMoa1 109653

18. Novartis Pharmaceuticals Corporation (2012) Afinitor (everolimus) prescribing information. East Hanover, NJ. http://www. pharma.us.novartis.com/product/pi/pdf/afinitor.pdf. Accessed 20 Mar 2013

19. Andre F, Campone M, O'Regan R, Manlius C, Massacesi C, Sahmoud T, Mukhopadhyay P, Soria JC, Naughton M, Hurvitz SA (2010) Phase I study of everolimus plus weekly paclitaxel and trastuzumab in patients with metastatic breast cancer pretreated with trastuzumab. J Clin Oncol 28(34):5110-5115. doi:10.1200/ JCO.2009.27.8549

20. Janku F, Pribylova O, Zimovjanova M, Pazdrova G, Safanda M, Zemanova M, Petruzelka L (2004) 4-years results of weekly trastuzumab and paclitaxel in the treatment of women with HER2/neu overexpressing advanced breast cancer: single institution prospective study. Bull Cancer 91(10):E279-E283

21. Zhou X, Tan M, Stone Hawthorne V, Klos KS, Lan KH, Yang Y, Yang W, Smith TL, Shi D, Yu D (2004) Activation of the Akt/ mammalian target of rapamycin/4E-BP1 pathway by ErbB2 overexpression predicts tumor progression in breast cancers. Clin Cancer Res 10(20):6779-6788

22. Chandarlapaty S, Sakr RA, Giri D, Patil S, Heguy A, Morrow M, Modi S, Norton L, Rosen N, Hudis C, King TA (2012) Frequent mutational activation of the PI3K-AKT pathway in trastuzumabresistant breast cancer. Clin Cancer Res 18(24):6784-6791. doi:10.1158/1078-0432.CCR-12-1785

23. Jegg AM, Ward TM, Iorns E, Hoe N, Zhou J, Liu X, Singh S, Landgraf R, Pegram MD (2012) PI3K independent activation of
mTORC1 as a target in lapatinib-resistant ERBB2+ breast cancer cells. Breast Cancer Res Treat 136(3):683-692. doi:10.1007/ s10549-012-2252-9

24. Gayle SS, Arnold SL, O'Regan RM, Nahta R (2012) Pharmacologic inhibition of mTOR improves lapatinib sensitivity in HER2-overexpressing breast cancer cells with primary trastuzumab resistance. Anticancer Agents Med Chem 12(2):151-162

25. U.S. Food and Drug Administration (2012) FDA approves Perjeta for type of late-stage breast cancer [news release]. http://www.fda. gov/NewsEvents/Newsroom/PressAnnouncements/ucm307549.htm. Accessed 20 March 2013

26. Baselga J, Cortés J, Im S-A, Clark E, Kiermaier A, Ross G, Swain SM (2012) Biomarker analyses in CLEOPATRA: a phase III, placebo-controlled study of pertuzumab in HER2-positive, firstline metastatic breast cancer (MBC). Presented at CTRC-AACR San Antonio breast cancer symposium, December 4-8, 2012, San Antonio, TX. Abstract S5-1

27. Morrow PK, Wulf GM, Ensor J, Booser DJ, Moore JA, Flores PR, Xiong Y, Zhang S, Krop IE, Winer EP, Kindelberger DW, Coviello J, Sahin AA, Nunez R, Hortobagyi GN, Yu D, Esteva FJ (2011) Phase I/II study of trastuzumab in combination with everolimus (RAD001) in patients with HER2-overexpressing metastatic breast cancer who progressed on trastuzumab-based therapy. J Clin Oncol 29(23):3126-3132. doi:10.1200/JCO.2010. 32.2321

28. Motzer RJ, Escudier B, Oudard S, Hutson TE, Porta C, Bracarda S, Grunwald V, Thompson JA, Figlin RA, Hollaender N, Kay A, Ravaud A (2010) Phase 3 trial of everolimus for metastatic renal cell carcinoma: final results and analysis of prognostic factors. Cancer 116(18):4256-4265. doi:10.1002/cncr.25219

29. Oberstein PE, Saif MW (2012) Safety and efficacy of everolimus in adult patients with neuroendocrine tumors. Clin Med Insights Oncol 6:41-51. doi:10.4137/CMO.S7319

30. Doi T, Muro K, Boku N, Yamada Y, Nishina T, Takiuchi H, Komatsu Y, Hamamoto Y, Ohno N, Fujita Y, Robson M, Ohtsu A (2010) Multicenter phase II study of everolimus in patients with previously treated metastatic gastric cancer. J Clin Oncol 28(11):1904-1910. doi:10.1200/JCO.2009.26.2923

31. O'Regan R, Ozguroglu M, Andre F, Toi M, Jerusalem G, Wilks S, Isaacs C, Xu B, Masuda N, Arena FP, Yardley D, Yap YS, Mukhopadhyay P, Douma S, El-Hashimy M, Taran T, Sahmoud T, Lebwohl D, Gianni L (2013) Phase III, randomized, doubleblind, placebo-controlled multicenter trial of daily everolimus plus weekly trastuzumab and vinorelbine in trastuzumab-resistant, advanced breast cancer (BOLERO-3). Presented at 2013 ASCO annual meeting, May 31-June 4, 2013, Chicago, IL. Abstract 505

32. Paplomata E, Zelnak A, O'Regan R (2013) Everolimus: side effect profile and management of toxicities in breast cancer. Breast Cancer Res Treat 140(3):453-462 